\title{
端 Sorvilo
}

Análisis

\section{Alumnos de educación superior con discapacidad física: retos y problemas en estrategias de intervención}

Gustavo Abdiel Ramírez Camberos*

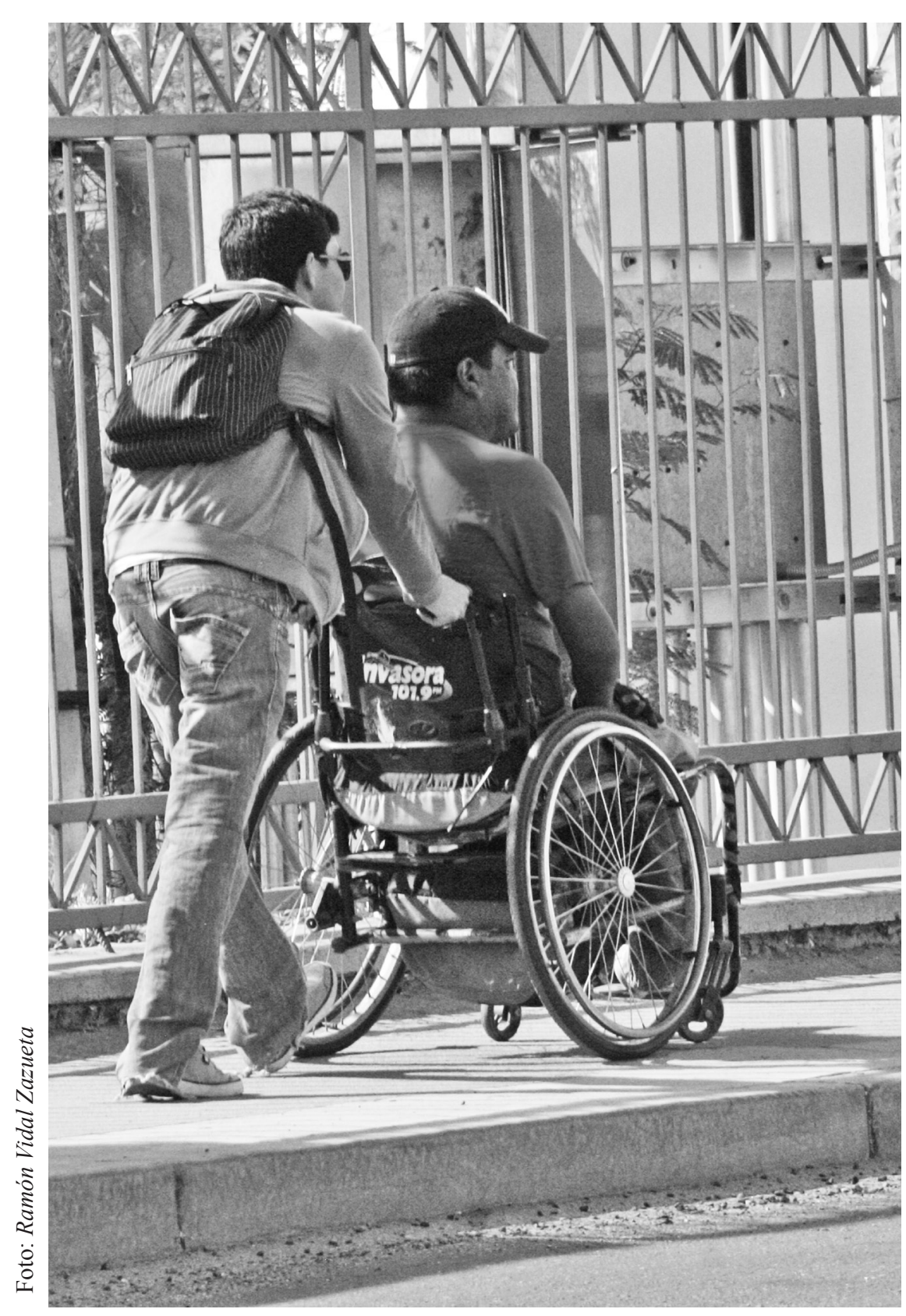

\section{Resumen}

Este artículo presenta una serie de reflexiones a partir de resultados parciales y descriptivos, del proyecto de investigación que sobre alumnos con discapacidad en educación superior; se desarrolla en el Departamento de Psicología y Ciencias de la Comunicación desde el año 2012. Se parte de dos casos presentados en la Universidad de Sonora, un alumno con discapacidad motriz y otro con discapacidad visual, a los cuales se les ha dado seguimiento a partir de entrevistas a profundidad y con la evaluación de sus trayectorias escolares; así su incorporación en proyectos de servicio social y proyectos de investigación. Se plantea que para la intervención en alumnos con discapacidad que cursan la educación superior tiene que integrar un equipo multidisciplinario que dé seguimiento a sus trayectorias escolares, promueva adecuaciones curriculares y trabaje incluso, con las familias de los sujetos.

\begin{abstract}
This paper presents a series of reflections from partial results and descriptive about research project on students with disabilities in higher education that takes place in the Department of Psychology and
\end{abstract}

\footnotetext{
* Licenciado en Ciencias de la Comunicación, Maestro en Comunicación por la Universidad Nacional Autónoma de México. Profesor del Departamento de Psicología y Ciencias de la Comunicación en la Universidad de Sonora. grc1971@psicom.uson.mx
} 


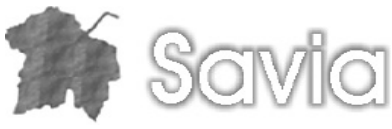

Communication Sciences from 2012. We start with cases reported in the University of Sonora, which have been followed from in-depth interviews and monitoring their school careers and by joining social service projects and research projects. We propose that for intervention in students with disabilities in higher education, has to integrate a multidisciplinary team to follow up on their schooling, promote curricular adjustments and work even with the families of the subjects.

\section{Introducción}

En la Universidad de Sonora, contexto institucional de la investigación, desde hace algunos años se han realizado adecuaciones a la infraestructura para lograr mejores condiciones para el desarrollo de las actividades educativas de alumnos que presentan alguna discapacidad física.

Se han multiplicado y se evidencia un crecimiento en la construcción de rampas de acceso, elevadores y cajones de estacionamiento para personas con discapacidad. La Biblioteca Central Universitaria tiene el Centro de acceso a la información para personas con discapacidad visual (CAIDIV), creado desde el 2001 y donde se cuenta con equipo de cómputo y software que facilitan la lectura y el trabajo académico de los alumnos con discapacidad visual

De igual forma, a los alumnos con estas condiciones que en su trayectoria escolar presentan algún tipo de riesgo, son incorporados al programa de tutorías y se les canaliza para que reciban atención de diversa índole, ya sea como apoyo a sus procesos de enseñanza aprendizaje o atención psicológica.

Independientemente de lo insuficiente que puedan resultar hasta el momento las adecuaciones a la infraestructura, o las dificultades para el acceso a segundos pisos de algunos edificios, o los problemas que se presentan por el no respeto a los espacios destinados a este grupo, los alumnos con discapacidad física presentan otro tipo de dificultades que requieren de un programa de acción aún más completo; un programa que permita su integración, tanto en el sentido infraestructural como didáctico y social del término, y que por alguna razón los programas institucionales de apoyo no han alcanzado a impactarlos positivamente.

\section{Los problemas de socialización}

Una de las dificultades que en su proceso de integración presentan los alumnos con discapacidad física es el proceso de socialización.

La microcomunidad estudiantil donde se inserten y la estabilidad que esta comunidad presente es importante en su desarrollo, ya que les permite no solamente el cumplimiento de las tareas asignadas, sino influye en aspectos emocionales como la autoestima.

El primer caso que se describe es un alumno con discapacidad visual, la cual se debe a la afectación por un síndrome (Usher). Sus problemas de visión se presentaron durante sus estudios de bachillerato, incidiendo tanto en el tiempo en el que cursó el nivel medio superior como en la cantidad de instituciones en las que se tuvo que inscribir y en su proceso de integración a la sociedad:

Tengo el campo periférico reducido, no distingo colores, tiene que ser un contraste muy fuerte y no tengo tercera dimensión, en la noche no veo nada, excepto las luces (Discapacidad visual, 2012).

El tránsito de este alumno por la universidad ha sido lento, ingresó a la licenciatura en Ciencias de la Comunicación con el plan de estudios anterior, 19842, se le incorporó al nuevo plan (2004-2) sin mejoría en el ritmo de su trayectoria escolar.

Casi no me toman en cuenta, me ignoran, me hacen a un lado, ya nomás al final me dicen lo que pasó (Discapacidad visual, 2012).

Con este comentario el alumno expresa que su proceso de integración a los equipos de trabajo en la universidad no se está resolviendo con eficacia; de hecho no hay integración y la comunidad solo se constituye en un agente que lo incluye en un equipo a fin de que obtenga una calificación aprobatoria. Al respecto el alumno establece:

Es lo que no quiero, terminar la materia y acreditarla y seguir siendo un mediocre, sin haber aprendido nada. No me es fácil adaptarme a cualquier equipo. (Discapacidad visual, 2012).

Y posteriormente comenta: 


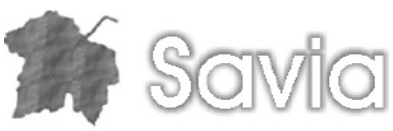

Bueno, en mi caso es que estoy solo contra el mundo, el sistema universitario te dice que te tienes que adaptar a un ritmo, si no, te quedas atrás, ese es uno de los problemas... tengo que competir contra mí mismo y contra el grupo y tengo que satisfacer al maestro para poder acreditar la materia (discapacidad visual, 2012).

De su testimonio se puede obtener la información de que la decisión de estudiar la carrera en la que está, fue influida por los problemas de integración que ya venía presentando y que además, los tenía identificados:

Pensé que estudiar esta carrera (Ciencias de la Comunicación) era más viable para mi condición y como siempre fui algo antisocial, pensé que esa carrera me pudiera ayudar más a desenvolverme mejor como persona, a ser más sociable, para integrarme a la sociedad (discapacidad visual, 2012).

Los problemas no han disminuido, incluso algunos han crecido, es decir, su paso por la universidad no ha influido en la disminución de las resistencias sociales que se le fueron desarrollando por la pérdida de la visión e incluso, al problema se le han incorporado elementos nuevos como las expectativas profesionales:

Eso es algo que pienso todos los días, la verdad, sinceramente, me siento... Ahorita no creo tener expectativas porque en todas las materias que he cursado me siento mediocre, siento que no he aprendido nada, como que nomás vengo a cumplir un requisito, como que estoy viniendo por un estándar de la sociedad, porque todo mundo dice que debo de tener una carrera para tener un trabajo. Sí, en eso he estado pensando, en qué voy a trabajar, qué voy a hacer, es algo desesperante la verdad (discapacidad visual, 2012).

En este caso, llegar a la conclusión de que se necesita tutoría especializada, tal vez no sea una conclusión del todo válida, porque el problema no es el qué hacer únicamente, sino el cómo hacerlo. Debemos preguntarnos a partir de qué elementos hacemos válido el principio de la integración educativa a nivel superior, con un alumno de estas características que no solo presenta problemas de discapacidad física, sino donde se involucran aspectos de personalidad y de expectativas personales.
Intervenir en este caso, se presenta como una tarea compleja, dado que es necesaria la participación de un colectivo interdisciplinario que de manera conjunta trabaje en el desarrollo de estrategias que permitan el desarrollo de sus procesos psicológicos, cognitivos $\mathrm{y}$ de haceres.

Para el segundo caso que se presenta, los problemas de socialización no han sido tan difíciles de resolver.

Es el caso de un alumno con discapacidad motriz. Ingresó a la universidad (Ciencias de la Comunicación) con muletas, posteriormente un accidente de trabajo le provocó daños irreversibles en las rodillas lo que le obligó a andar en silla de ruedas. Su condición socioeconómica no es fácil. Al momento de la entrevista tenía dos trabajos y por la tarde venía a la escuela.

Su tránsito académico por la universidad también ha sido lento e inclusive se le había integrado mediante revalidación, al nuevo plan de estudios (2004-2), sin embargo al momento de la entrevista se acordó que mantendría en el plan 84-2. Se dificultó su registro en el servicio social por el porcentaje de créditos que presentaba y por desajustes en la modificación al plan de estudios con el que egresará. Ha hecho uso de servicios psicológicos en su trabajo.

Este alumno con discapacidad motriz presenta menos problemas de integración a grupos de trabajo, así lo evidencian tanto su narración como el seguimiento de sus interacciones por observación. $\mathrm{Su}$ grupo de amigos de tres o cuatro alumnos se mantuvo más o menos estable desde que entraron a la universidad y hasta que egresaron.

En métodos (...) cuando tengo que hacer investigación de campo, no puedo andar en camiones o trasladarme a cierta escuela o cierto espacio; en mi trabajo de la compañía de taxis me hacen descuento; yo pago 50 pesos diarios de ida y de venida; soy radio operador; dejo medio sueldo ahí, y con el otro pues a apoyar en mi casa, agua, luz, internet, comida (discapacidad motriz, 2012).

Se infiere que el problema de la integración a los grupos con los alumnos con necesidades educativas especiales no es exclusivo del espacio áulico o de los pasillos, este se extiende al trabajo de campo 


\section{繶 Scovita}

o extramuros que los alumnos tienen que realizar.

\section{Trayectorias escolares}

El nivel de reprobación que presentan alumnos con discapacidad no es un estándar, es decir, por las aulas universitarias han pasado alumnos con distintos tipos y niveles de discapacidad, que han logrado concluir sus estudios universitarios en el tiempo administrativamente establecido; sin embargo, los fragmentos de testimonios que aquí se presentan, acusan un problema de trayectorias escolares que necesita mayor atención.

Otro de los problemas es que no hay materias adaptables para mí, adecuados para mí; reprobé tres veces estadística, me la tuve que llevar a especial; la inferencial ya la llevé dos veces y no quiero llevarla por tercera vez porque no me quiero ir a especial; entonces, ahí no hay nada para mí en estadística, problemas matemáticos que los resuelven, los ven en el pizarrón, como yo no veo (discapacidad visual, 2012).

Ambos alumnos presentan un agudo retraso en su trayectoria escolar y evidencian la necesidad de una atención más individualizada.

La mayoría de los maestros no me dan un trato especial o preferente, no me preguntan ¿tú puedes?, no me toman en cuenta, tampoco me voy a poner a decir no puedo (...) no pido un trato preferencial: lo que sí me gustaría es que nos pusieran más atención, como somos poquitos, es más viable que se nos ponga más atención (discapacidad motriz, 2012).

He tenido dificultades en matemáticas, cómputo, por ejemplo, nuevas tecnologías y en las materias en donde se requiere a fuerzas equipo, a excepción de fotografía donde tuve un maestro muy bueno (...) me apoyó, me enseñaba cosas nuevas: cómo se usa una cámara, para qué sirve cada botón... En la creatividad, me daba ejemplos, hacía que pensara, me describía las imágenes, con el paso del tiempo se ha hecho una amistad (discapacidad visual, 2012).

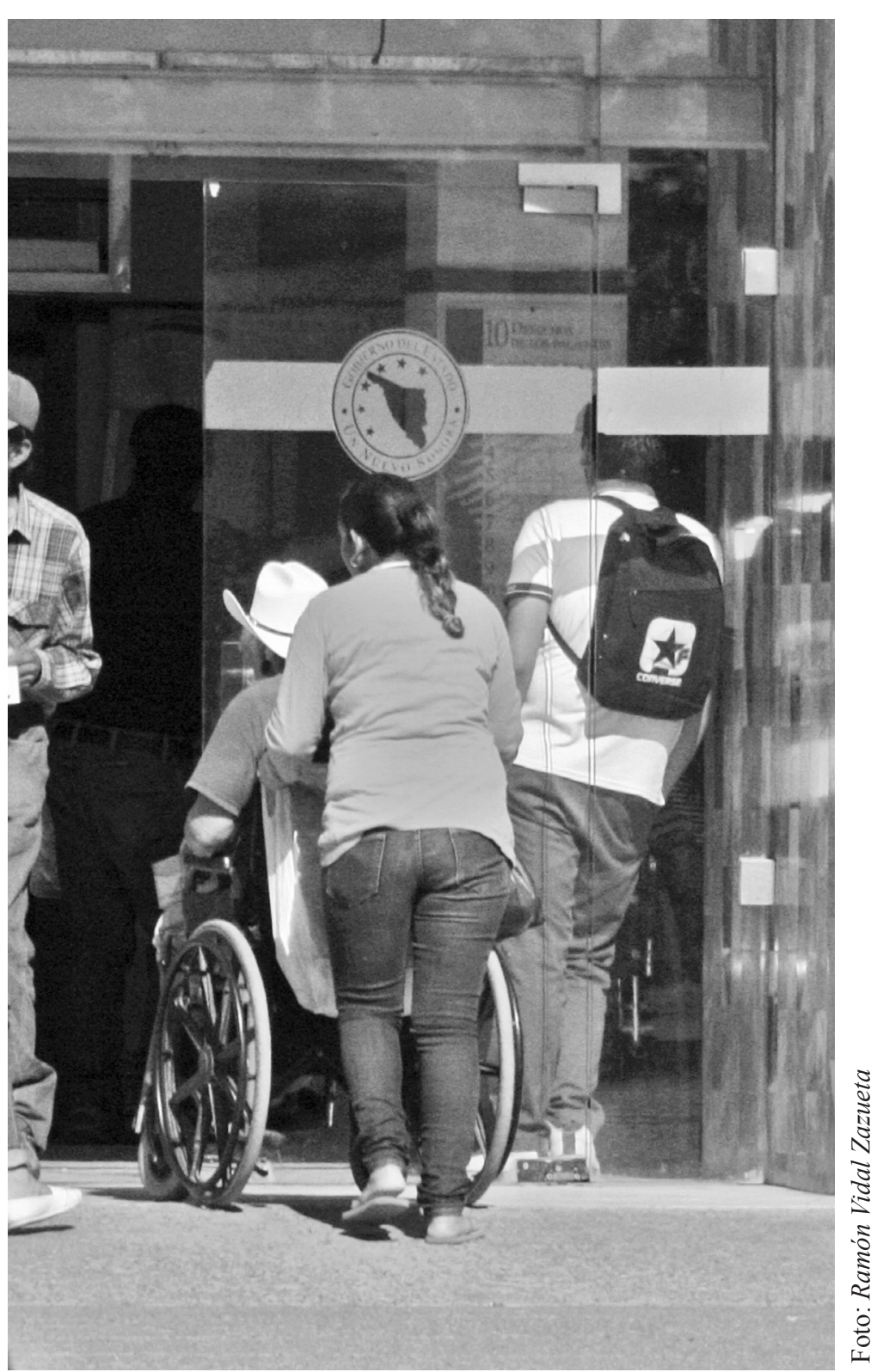

En el siguiente fragmento testimonial, la variable infraestructura se cruza con el aprovechamiento escolar:

En las plantas bajas no hay problema, pero he batallado cuando son en las altas: me baja mucho el promedio por las faltas, batallo mucho para que me puedan cambiar de salón, algunos maestros no quieren cambiar de aula (discapacidad motriz, 2012).

Ambos aspectos: socialización y trayectorias escolares, son importantes en los programas de intervención que las instituciones educativas 


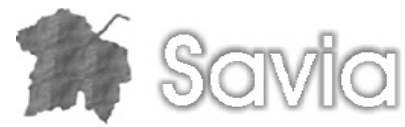

desarrollan o pueden desarrollar y mediante los cuales se trata de impactar positivamente en el aprovechamiento del estudiante.

\section{Enfrentando los retos de la intervención}

Los fragmentos de testimonios aquí presentados plantean retos para la intervención en alumnos con discapacidad y evidencian problemas que no han sido cubiertos pese a los esfuerzos realizados, tanto a nivel financiero como a nivel de capacitación y de diseño de programas institucionales de trabajo con el alumnado.

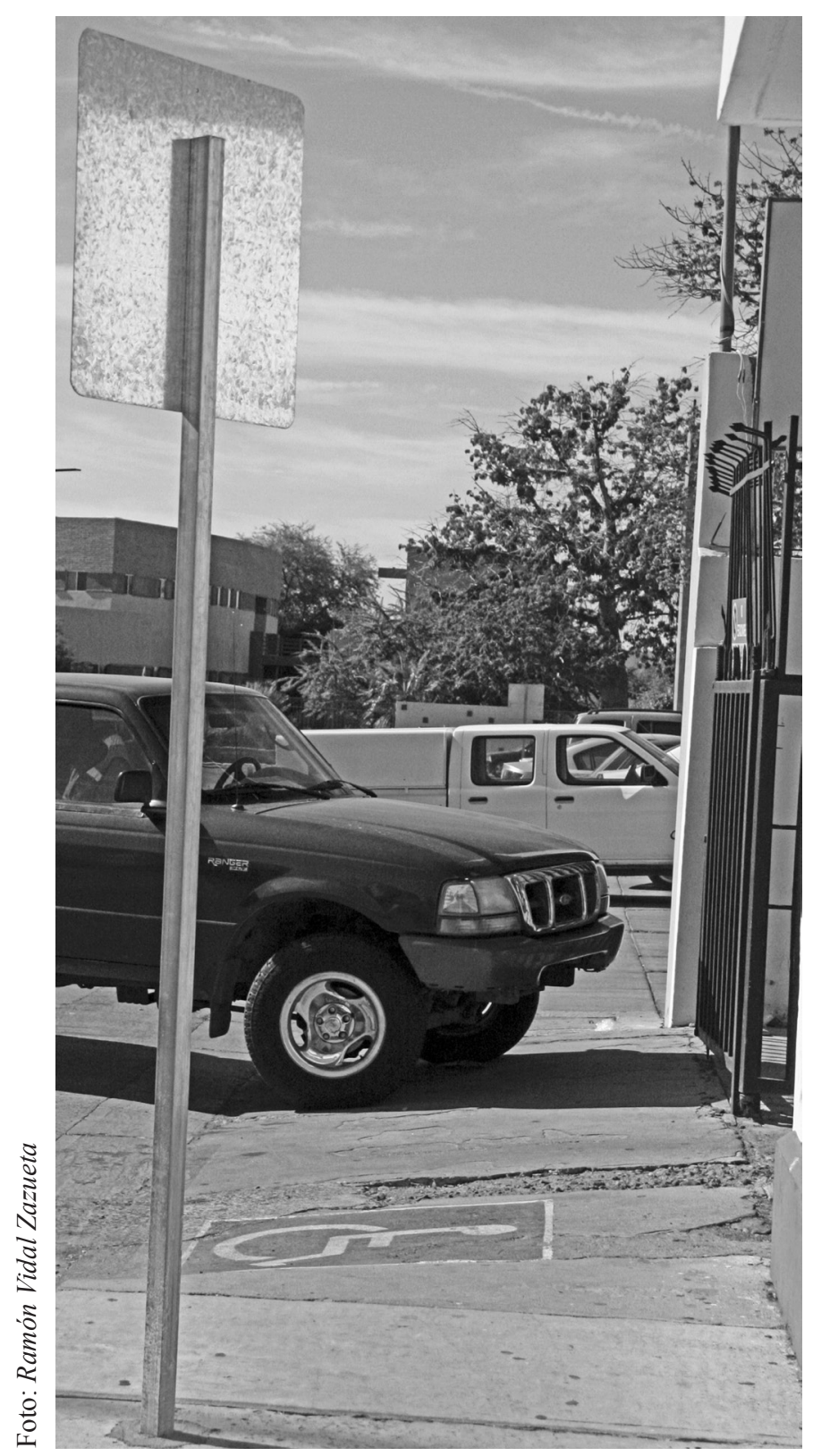

Para el caso específico de la Universidad de Sonora, es importante que la inversión realizada en infraestructura para apoyo a personas con discapacidad, se vea reforzada con el trabajo académico que se les puede brindar a estos alumnos a través de un programa integral de apoyo a estudiantes con discapacidad.

Es muy difícil que la tutoría individualizada tenga impactos definitivos en los problemas de trayectorias escolares y de integración social que presentan los alumnos con discapacidad física.

Los docentes no estamos informados ni formados para conocer y atender aspectos básicos de trabajo educativo con personas con algún tipo de discapacidad, ni física ni intelectual. Entre lo masivo de los grupos a los que cotidianamente atiende un profesor promedio y la diversidad de actividades, es difícil la construcción de procesos educativos llevados hasta niveles muy precisos de necesidades individuales.

Si el docente intenta acercarse al problema para intervenir de manera individual, la efectividad de su acción se ve limitada al espacio educativo que atiende y a la generación de una relación de amistad, como ya lo vimos en uno de los testimonios, que si bien es cierto juega un papel importante, no es el objetivo final.

Considerando todos los obstáculos expuestos, y aun los que se sabe existen y no fueron señalados, la atención de alumnos con discapacidad tiene que partir de una estrategia colegiada de intervención multidisciplinaria e interdisciplinaria. Esta intervención puede enfocarse en áreas como:

- Formación e incorporación a equipos de trabajo

- Estrategias de enseñanza aprendizaje

- Apoyo psicológico

- Trayectorias escolares

- Relaciones familiares y entornos laborales

A nivel general, la investigación sobre educación especial a nivel superior está escasamente desarrollada, es importante la generación de datos a distintos niveles a fin de incorporarlos a la toma de decisiones institucionales sobre los alumnos con discapacidad física. 
Bajo estas premisas, se plantea que la intervención en alumnos con discapacidad en las instituciones de educación superior, implica la siguiente ruta:

- Generación de información: creación de un programa de investigación específico y a nivel institucional sobre alumnos con discapacidad que permita obtener información para detectar necesidades muy particulares.

- Integración de colegiados multidisciplinarios: que a partir de atención conjunta y reuniones periódicas, tanto internas como con los sujetos en cuestión, discutan y apliquen instrumentos de diagnóstico y de intervención en las áreas ya mencionadas.

- Inclusión de temas sobre discapacidad en los programas de capacitación: que el personal docente pueda disponer de información básica que permita atender, desde aspectos emocionales, tales como la generación de empatía, hasta la elaboración de criterios específicos de evaluación y de asignación de actividades a alumnos con discapacidad, dependiendo del tipo de discapacidad que presente y de sus dificultades para la integración.

\section{Comentarios finales}

El proyecto de investigación continúa con el doble propósito de generar información sobre este grupo de estudiantes por una parte; y por otro, el de impulsar la discusión sobre la incorporación de alumnos con distintos tipos de discapacidades a los programas de intervención institucionales, a partir de acciones específicas que tengan un mayor éxito en el desempeño de estos estudiantes.

Será importante recoger las experiencias de los docentes y de los encargados de los programas de atención a estudiantes para contrastar y aportar mayores elementos en la toma de decisiones.

El reto en cuanto a la estrategia de intervención en alumnos con discapacidad física y de cualquier tipo es importante, no por la relevancia estadística de este grupo, la cual tal vez no alcance ni $1 \%$ de la población estudiantil, sino por el cumplimiento de una vocación social de las instituciones de educación superior, y por la necesidad de generar procesos educativos más incluyentes.

\section{Bibliografía}

Cervantes Alducín, Rosa María. (2011). Importancia de la filosofía de la educación. En: Carmen Romano Rodríguez, y Jorge Fernández Pérez (comps.) Filosofía y Educación: perespectivas y propuestas (pp. 250). Puebla: BUAP.

Consejo Nacional para el Desarrollo e Inclusión de Personas con Discapacidad. Extraído el 30 de septiembre de 2013, de: http://www.conadis. salud.gob.mx/descargas/pdf/glosario_terminos sobre_discapacidad.pdf

Denman Champion, Catalina. A. y Jesús Armando Haro Encinas. (2000). Por los rincones. Antología de métodos cualitativos en investigación social. Hermosillo, Sonora, México: El Colegio de Sonora.

Diaz Barriga, Angel. (1993). Tarea docente. México: Nueva Imagen.

Entrevista 1, estudiante con discapacidad visual (6 de febrero de 2012).

Entrevista 2, estudiante con discapacidad motriz (11 de febrero de 2012).

González Lizárraga, María Guadalupe. (2004). Perfil de ingreso de los estudiantes de la Universidad de Sonora. Hermosillo, Sonora, México: Universidad de Sonora.

(2011). Trayectorias universitarias, integración y experiencia. Barcelona: EAE.

Hernández Hernández, Guillermo y Jorge Fernández Pérez. (2010). Expectativas profesionales: un estudio de caso. Revista Mexicana de Orientación Educativa, 7 (19), 18-27.

Hernández Sampieri, Roberto, Carlos Fernández Collado y Pilar Baptista Lucio. (2003). Metodología de la Investigación Social (3 ${ }^{\mathrm{a}}$ ed.). México: McGraw Hill.

Meneses Benítez, Gerardo. (2007). NTIC, interacción $y$ aprendizaje en la universidad. Tesis doctoral. Barcelona. 